American Journal of Applied Sciences 4 (4): 233-236, 2007

ISSN 1546-9239

(C) 2007 Science Publications

\title{
Thickness Analysis of Stone Mastic Asphalt (SMA) Slab Compacted Using a Newly Developed Roller Compactor
}

\author{
Muniandy, R., Jakarni, F.M., Hassim, S. and Mahmud, A.R. \\ Department of Civil Engineering, Faculty of Engineering, Universiti Putra Malaysia \\ 43400 UPM Serdang, Selangor, Malaysia
}

\begin{abstract}
Pavement mix design procedures and specifications are usually derived from laboratory experiments. Therefore, laboratory experiments should be able to simulate to a high degree the conditions in the field, especially in term of compaction procedures. Based on literature reviews and analysis of past studies, it can be concluded that there are no exact method for laboratory compaction that can simulate field compaction procedures. Turamesin, a newly developed laboratory compaction device has been designed to provide a solution to the problem of producing laboratory specimens which are representative of materials laid and compacted in the field. This study reports on the evaluation of the thickness of the compacted slabs and analysis of the consistency of the measured parameter. A total of 15 slabs from three different types of asphalt binders, namely Grade 60/70, Grade PG76 and Grade 80/100 were prepared, measured and analyzed. Based on statistical analysis conducted, the compacted slabs were found to have an average area of $590 \mathrm{~mm}$ of length by $500 \mathrm{~mm}$ of width and thickness ranging from $60 \mathrm{~mm}$ to $68 \mathrm{~mm}$. The compacted slabs were found to have problems in terms of the difference in thickness between left-side and right-side of the slab that occurred due to unequal load distribution from the roller compactor. The results obtained from this study will lead to development of Turamesin as an improved laboratory compaction device.
\end{abstract}

Key words: Asphalt mixtures, laboratory compaction, slab, roller compactor

\section{INTRODUCTION}

Mix design procedures and specifications are usually derived from laboratory experiments since laboratory conditions are less time consuming and relatively easy to control. Therefore, laboratory experiments should be able to simulate to a high degree the conditions in the field, especially in term of compaction procedures. It is important to understand that if the field conditions for which the mixtures are being designed for are different from those for which the design method was developed, the mixtures may not be adequate for service even though it is designed according to the method $\mathrm{d}^{[1,2]}$.

The presently available laboratory compaction procedures have intrinsic limitations due to different modes in mechanical manipulation of the mixtures and different energy levels of compaction compared with field compaction ${ }^{[1-3]}$. Several studies have concluded that Marshall Impact Compactor, California Kneading Compactor and Gyratory Shear Compactor do not seem to be able to produce laboratory specimens that can truly represent the asphalt mixtures as it exists in the field, especially for Stone Mastic Asphalt (SMA) mixtures ${ }^{[4-8]}$. SMA is one type of asphalt mixtures consisting of higher asphalt content and coarser aggregates skeleton and therefore is highly dependent on the method of compaction as compared to conventional Hot Mix Asphalt (HMA) mixtures. Thus, the available laboratory compaction procedures may result in less accurate and unrealistic data for pavement design and thus may lead to poor performance of pavement construction.

Turamesin, a newly developed laboratory compaction device has been designed to provide a solution to the problem of producing laboratory specimens which are representative of materials laid and compacted in the field. Since Turamesin has been designed to match that of field compaction equipment in term of operational procedure, therefore Turamesin was expected to better simulate field compaction equipment compared to the existing laboratory compaction devices $^{[9,10]}$. As part of the verification of Turamesin as laboratory compaction device, a study to determine the extent to which the properties of slabs compacted under similar conditions vary among each other is essentially required. This study was conducted in order to evaluate and analyze the consistency of thickness of the Stone Mastic Asphalt (SMA) slabs compacted using Turamesin. This effort was basically a sensitivity study to determine if significant different in thickness exist between slabs which have been designed for a target thickness of $70 \mathrm{~mm}$.

Background: Turamesin is used to compact asphalt mixtures using a steel wheel roller just like the heavy duty steel wheel roller on-site. Different levels of pressure can be applied up to approximately 10.0 $\mathrm{kgf} / \mathrm{cm}^{2}$ (142 psi) developed by a pneumatic system, supplied through air compressor ${ }^{10]}$. Figure 1 shows the

Corresponding Author: $\quad{ }^{1}$ Muniandy, R. \& ${ }^{2}$ Jakarni, F.M., Department of Civil Engineering, Faculty of Engineering, Universiti Putra Malaysia, 43400 UPM Serdang, Selangor, Malaysia, Tel: ${ }^{2}+60389464421$, Fax: $+60386567129$ 
Turamesin device which has the overall length of about $930 \mathrm{~mm}$ and the overall width of $870 \mathrm{~mm}$, whereas the overall height is $474 \mathrm{~mm}$. The dimension of $930 \mathrm{~mm}$ by $870 \mathrm{~mm}$ by $474 \mathrm{~mm}$ shows that Turamesin has a small size compared to the existing compacting devices thus makes Turamesin as a very portable device that can be used in the field for quality control operations.

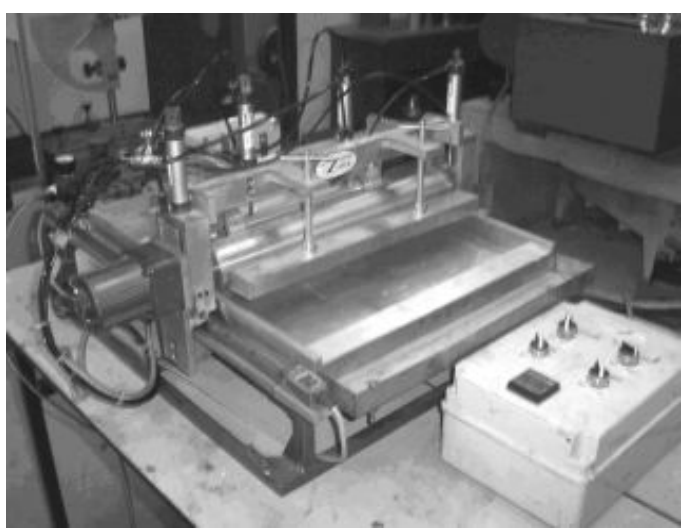

Fig. 1: Turamesin

A study to identify the basic principles and criteria of Turamesin related to slab preparation and compaction was completed and an in-house procedure as guidance or manual in operating Turamesin was developed $^{[10,11]}$. Based on the studies, $8.0 \mathrm{kgf} / \mathrm{cm}^{2}$ of applied pressure and 75 numbers of passes were identified as being significantly important in controlling the compaction efforts to result in the asphalt mix slab with closest properties to in-service pavement due to $4 \%$ air voids. These values are considered as typical parameters for slab compaction using Turamesin in achieving $4 \%$ air voids.

\section{MATERIALS AND METHODS}

In order to consider a range of SMA mixtures, three types of asphalt binders were utilized, namely Grade 60/70, Grade PG76 and Grade 80/100. Mineral aggregates used consisted of $14 \mathrm{~mm}$ nominal maximum aggregates size of granite and limestone as mineral filler. Palletized cellulose fibers (VIATOP 80-20) were used as an additive in SMA mixtures. Fibers were added to the asphalt mixtures at a dosage rate of $0.3 \%$ by total weight of the mixtures. Aggregates and different types of asphalt binders were subjected to physical property tests to conform to the specification requirements. All the test results were conformed to the specification requirements.

Five slabs were prepared for three different types of asphalt binders that make up to a total of 15 slabs for overall study. Determination of the optimum asphalt content for each type of asphalt binders was done through Marshall mix design analysis in accordance with ASTM D1559-89 and the optimum asphalt content value were found to be $5.60 \%$ for Grade $60 / 70,6.04 \%$ for Grade PG76 and $6.05 \%$ for Grade 80/100 respectively. A target value of $4 \%$ for the air voids was used in calculating the amount of materials required for each slab, based on volume-density calculations. Each compacted slab was then measured for thickness. Each recorded data was then analyzed to determine the consistency of the measured parameter among slabs.

\section{RESULTS AND DISCUSSION}

Table 1 shows the average thickness of the left-side and the right-side respectively, measured at five different points for each slab and also the difference in thickness between left-side and right side. It is noted that the average thickness for the left-side and the rightside was $66.56 \mathrm{~mm}$ and $60.44 \mathrm{~mm}$ respectively for Grade 60/70, $67.32 \mathrm{~mm}$ and $62.48 \mathrm{~mm}$ respectively for Grade PG76 and $65.72 \mathrm{~mm}$ and $60.48 \mathrm{~mm}$ respectively for Grade 80/100.

SMA slabs compacted in this study were designed to a target thickness of $70 \mathrm{~mm}$ although the thickness can be varied according to user requirement up to 100 $\mathrm{mm}$. The general procedure for analysis basically consists of performing a descriptive statistics analysis to determine the average, standard deviation and coefficient of variation. Coefficient of variation (COV) was used to evaluate and compare the variation between data sets. Twenty-five percent or less is desirable for cutoff value of coefficient of variation ${ }^{[12]}$. Since there is no exact cutoff value, a predefined cutoff thresholds value of $10 \%$ was used in this study to control the consistency level of the data sets.

Based on data in the table, there was a significant difference in thickness between left-side and right-side. Theoretically, there should be no difference in thickness as slab was designed to a target thickness of $70 \mathrm{~mm}$ throughout the entire section. A hypothesis testing involves One-Sample t-Test procedure, at level of significance, $\alpha$ of 0.05 , was conducted to determine whether there is evidence of significant difference in thickness between left-side and right-side. The following hypotheses were then established.

The null hypothesis, $\mathrm{H}_{\mathrm{o}}$

$\mathrm{H}_{\mathrm{o}}: \mu_{(\mathrm{Ln}-\mathrm{Rn})}=0$ (The average difference in thickness between left-side and right-side is zero)

The alternative hypothesis, $\mathrm{H}_{1}$

$\mathrm{H}_{1}: \mu_{(\mathrm{Ln}-\mathrm{Rn})} \neq 0$ (The average difference in thickness between left-side and right-side is not zero)

Based on MINITAB statistical analysis, the tstatistic, $T$ was found to be 25.75 and the $p$-value was found to be 0.000 (Fig. 2). 
Am. J. Applied Sci., 4 (4): 233-236, 2007

\begin{tabular}{|c|c|c|c|c|c|c|c|c|c|}
\hline \multirow[b]{2}{*}{ Slab } & \multicolumn{3}{|c|}{ Asphalt Mixtures Grade 60/70 } & \multicolumn{3}{|c|}{ Asphalt Mixtures Grade PG76 } & \multicolumn{3}{|c|}{ Asphalt Mixtures Grade 80/100 } \\
\hline & 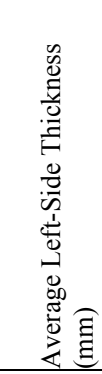 & 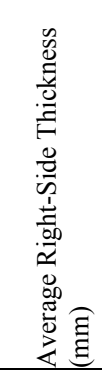 & 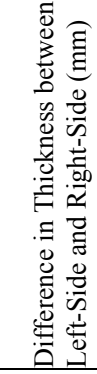 & 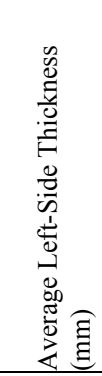 & 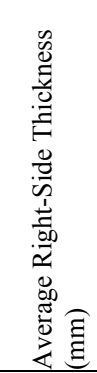 & 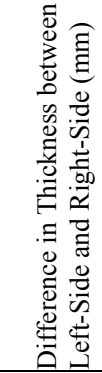 & 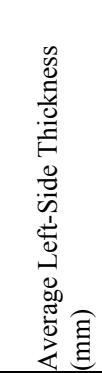 & 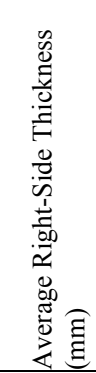 & 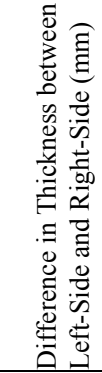 \\
\hline Slab 1 & 66.00 & 60.20 & 5.80 & 67.80 & 62.00 & 5.80 & 66.00 & 60.40 & 5.60 \\
\hline Slab 2 & 68.20 & 61.20 & 7.00 & 67.40 & 63.20 & 4.20 & 65.80 & 61.20 & 4.60 \\
\hline Slab 3 & 65.80 & 61.40 & 4.40 & 69.20 & 63.20 & 6.00 & 65.60 & 59.80 & 5.80 \\
\hline Slab 4 & 67.60 & 60.20 & 7.40 & 67.00 & 62.80 & 4.20 & 66.40 & 60.60 & 5.80 \\
\hline Slab 5 & 65.20 & 59.20 & 6.00 & 65.20 & 61.20 & 4.00 & 64.80 & 60.40 & 4.40 \\
\hline Average & 66.56 & 60.44 & 6.12 & 67.32 & 62.48 & 4.84 & 65.72 & 60.48 & 5.24 \\
\hline Std.Dev. & 1.28 & 0.89 & 1.17 & 1.45 & 0.87 & 0.97 & 0.59 & 0.50 & 0.68 \\
\hline Coeff. of Var. (\%) & 1.92 & 1.47 & 19.14 & 2.15 & 1.39 & 20.12 & 0.90 & 0.83 & 13.06 \\
\hline
\end{tabular}

The critical t-values were found to be \pm 1.9924 , based on (75-1) degrees of freedom and area in two tails of $(0.025+0.025)$. Therefore, based on the value of t-statistic, $\mathrm{T}$ of 25.75 , critical t-values of \pm 1.9924 and also p-value of 0.000 , the null hypothesis, $\mathrm{H}_{\mathrm{o}}$ is rejected at the level of significance, $\alpha$ of 0.05 . The analysis shows that significance statistical difference exists in thickness between left-side and right-side. The average difference in thickness was $5.40 \mathrm{~mm}$, in contrast to theoretical difference in thickness of zero.

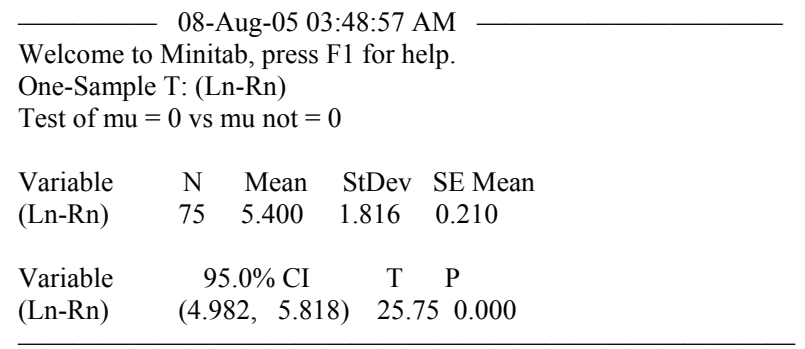

Fig. 2: MINITAB statistical analysis

The difference in thickness between left-side and right-side was found to occur due to unequal load distribution on the slab from the roller compactor during the compaction process. Motor, which is attached to one side of the roller compactor, has caused an additional load and thus reduce the thickness on the respective side. Therefore, a proper adjustment should be made to balance the weight of the roller compactor so that an equally distributed load can be applied on the slab surface.
Also, the thickness of the slab was found to be less than the target thickness of $70 \mathrm{~mm}$. This can possibly be attributes to many factors, but is most likely due to the whole process of sampling, mixing, transferring the asphalt mixtures and compacting which resulted in some of the mixtures to be left behind. Although, the thickness was found to be less than the target thickness of $70 \mathrm{~mm}$, it had no significant effect on slab properties. A tolerance of $\pm 10 \mathrm{~mm}$ offset from the target thickness is allowed since the measurements of thickness were recorded manually. However, careful measurements should be taken prior to compaction process in order to minimize the amounts of leftover mixtures.

Based on statistical analysis conducted, the compacted slabs were found to have an average area of $590 \mathrm{~mm}$ of length by $500 \mathrm{~mm}$ of width and thickness ranging from $60 \mathrm{~mm}$ to $68 \mathrm{~mm}$. The compacted slabs were found to have problems in terms of the difference in thickness between left side and right side of the slab. In the near future, Turamesin will be equipped with optical decoder to control and measure the thickness of the compacted slab. Therefore, the target thickness of the compacted slab is expected to be achieved within a small tolerance with the implementation of the optical decoder, on the condition that the problem due to unequal load distribution is solved.

\section{ACKNOWLEDGEMENTS}

The authors would like to thank the Department of Civil Engineering of Universiti Putra Malaysia for providing facilities and support to this project and to all 
the people whom are directly and indirectly involved in the project for their help and cooperation in this study.

\section{REFERENCES}

1. Consuerga, A., D.N. Little, H.V. Quintus and J. Burati, 1992. Comparative evaluation of laboratory compaction devices based on their ability to produce mixtures with engineering properties similar to those produced in the field. Transportation Research Record, 1228: 80-87.

2. Khan, Z.A., H.I. Wahab, I. Asi and R. Ramadhan, 1998. Comparative study of asphalt concrete laboratory compaction methods to simulate field compaction. Construction and Building Materials, 12: 373-384.

3. Button, J.W., D.W. Little, V. Jagadam and O.J. Pendleton, 1992. Correlation of selected laboratory compaction methods with field compaction. Texas Transportation Institute.

4. Goetz, W.H., 1989. The evolution of asphalt concrete mix design. ASTM Special Technical Publication, 1041.

5. Masad, E., B. Muhunthan, S. Naga and H. Thomas, 1999. Quantifying laboratory compaction effects on the internal structure of asphalt concrete. Transportation Research Record, 168: 179-185.
6. Maupin Jr, G.W., 1998. Final report-Comparison of several asphalt design methods. Virginia Transportation Research Council.

7. Smith, H.R. and C.R. Jones, 1998. Bituminous surfacing for heavily trafficked roads in tropical climates. Proc. institution of Civil Engineering Transportation, 129: 28-33.

8. Sousa, J.B., J.A. Deacon and C.L. Monosmith, 1991. Effect of the laboratory compaction methods on permanent deformation characteristics of asphalt aggregate mixtures. Proceedings Association of Asphalt Paving Technologist, 60: 533-585.

9. Muniandy, R., Not Dated. Turamesin. Universiti Putra Malaysia, Malaysia.

10. Zaharudin, M.F. and R. Muniandy, 2004. Evaluation of Turamesin for SMA slab compaction. B.Sc. Thesis, Universiti Putra Malaysia, Malaysia.

11. Jakarni, F.M. and R. Muniandy, 2006. Evaluation of Stone Mastic Asphalt Properties Using the Newly Developed Roller Compactor. M.Sc. Thesis, Universiti Putra Malaysia, Malaysia.

12. Volodin, A. and P. Nom, N.D., Quandaries and Queries. In Math Central. Retrieved Sep. 28, 2005, from http://www.mathcentral.uregina.ca. 